Çukurova Üniversitesi Mühendislik Fakültesi Dergisi, 36(2), ss. 473-482, Haziran 2021

Cukurova University Journal of the Faculty of Engineering, 36(2), pp. 473-482, June 2021

\title{
Aktif Tektonikte Uzaktan Algılama Uygulamaları: Doğu Anadolu Fay Zonu'ndan Bir Örnek
}

\author{
Elif AKGÜN*1, Murat İNCEÖZ ${ }^{1}$, Hatice Seval MANAP² \\ ${ }^{1}$ Fırat Üniversitesi, Mühendislik Fakültesi, Jeoloji Mühendisliği Bölümü, Elazı̆̆ \\ ${ }^{2}$ Akdeniz Üniversitesi, Mühendislik Fakültesi, Jeoloji Mühendisliği Bölümü, Antalya
}

Geliş tarihi: 22.04.2021 Kabul tarihi: 30.06 .2021

\section{$\ddot{O} \mathbf{z}$}

Uzaktan algılama uygulamaları, aktif tektonik çalışmalarında yapısal unsurların belirlenmesi ve diri fay haritalarının hazırlanmasında saha çalışmalarına kolaylık sağlamaktadır. Bu çalışmada, Türkiye'nin en önemli aktif tektonik unsurlarından biri olan Doğu Anadolu Fay Zonu'nun (DAFZ) orta kısmı konu edilmiştir. SRTM, Landsat 8 OLI ve ASTER gibi açık erişimli uydu görüntüleri uzaktan algılama yöntemleriyle işlenerek aktif tektonik çalışmalarında önemli rol oynayan morfotektonik yapılar belirlenmiş ve yorumlanmıştır. Landsat 8 uydu görüntüsünün yüksek mekânsal çözünürlüğe sahip pankromatik 8. Band ve SRTM görüntülerinin birleştirilmesi ile ana tektonik hatlar daha belirgin hale gelmiştir. ASTER uydu görüntülerine uygulanan bant kombinasyonu, kenar germesi, dekorelasyon germesi ve temel bileşen analizi gibi zenginleştirme teknikleri, kontrastı artırarak görüntünün yorumlanmasını kolaylaştırmıştır. Tektonik hatların yanı sıra akarsu ötelenmeleri, basınç sırtları, çizgisel vadi gibi morfotektonik özelliklerin ve litolojik sınırların ayırt edilmesinde ASTER görüntüleri multispektral özelliği ile belirleyici olmuştur. Tüm bu çalışmaların sonucunda, DAFZ üzerindeki sol yanal atımlar ortaya çıkarılmıştır.

Anahtar Kelimeler: SRTM, Landsat 8 OLI, ASTER, Doğu Anadolu fay zonu, Aktif tektonik

\section{Remote Sensing Applications in Active Tectonics: An Example from the Eastern Anatolian Fault Zone}

\begin{abstract}
Remote sensing applications facilitate field studies in the determination of structural elements in active tectonic studies and the preparation of active fault maps. In this study, the middle part of the East Anatolian Fault Zone (EAFZ), which is one of the most active tectonic elements of Turkey, was entreated. The morphotectonic structures that play a significant role in active tectonics were determined and interpreted by processing open-access satellite images such as SRTM, Landsat 8 OLI, and ASTER with remote sensing methods. With the combination of the SRTM images and the panchromatic 8th Band of Landsat 8 satellite images with high spatial resolution, main tectonic lines became more evident. Enhancement techniques such as band combination, edge stretching, decorelation stretching, and principal component analysis applied to ASTER satellite images expedited the interpretation of the image by increasing the contrast. In addition to tectonic lines, ASTER images with their multispectral feature were determinant in distinguishing morphotectonic features such as stream displacements, pressure
\end{abstract}

*Sorumlu yazar (Corresponding author): Elif AKGÜN, efiratligil@firat.edu.tr 
ridges, linear valleys, and lithological boundaries. As a result of all these studies, sinistral offsets on the EAFZ were revealed.

Keywords: SRTM, Landsat 8 OLI, ASTER, East Anatolian fault zone, Active tectonic

\section{GİRiş}

Uzaktan algılama uygulamaları mekânsal ve spektral çözünürlüklere sahip uydu görüntülerinin, amaca uygun yöntemlerle işlenmesine ve yorumlanmasına dayanmaktadır [1]. Birçok disiplinde olduğu gibi yer bilimlerinde de oldukça yaygın ve etkin bir şekilde kullanılmakta olup saha çalışması öncesi inceleme alanının uzaktan algılama yöntemleri ile incelenmesi, aktif tektonik çalışmalarında büyük kolaylık sağlamaktadır. Özellikle engebeli ve ulaşımı zor arazi koşullarına sahip bölgelerde gerçekleştirilen uzaktan algılama uygulamaları sahayı birçok yönden inceleyebilme konusunda oldukça avantajlıdır.

Aktif tektonik çalışmalar yeryüzünün kırılgan kısmı boyunca gelişmiş zayıflık zonları olarak bilinen fayları ve çizgisellikleri incelemektedir. Tektonik hatların belirlenmesinin yanı sıra; çalışma alanındaki çizgiselliklerin saptanması ve yorumlanması çalışma alanının aktif tektoniğinin ve deformasyon mekanizmasının anlaşılmasına büyük katkı sağlamaktadır. Özellikle de doğrultu atımlı faylar çizgisellik analizi için çok sayıda yapısal çeşitlilik (ana yer değiştirme zonu, antitetik ve sintetik kırıklar, p kırıkları, genişlemeli ve sıkışmalı yapılar) sergilemektedir [2]. Bu kapsamda, Türkiye'nin en önemli fay zonlarından biri olan DAFZ'nin aktif tektonik özellikleri, uydu görüntülerini zenginleştirme ve işlemeye dayalı uzaktan algılama çalışmaları ile incelenmiştir. Çalışma, Arabistan ile Avrasya levhaları arasındaki yakınsamaya bağlı gelişmiş kıta içi doğrultu atım karakteri sergileyen DAFZ'nin orta kısmını kapsamaktadır (Şekil 1).

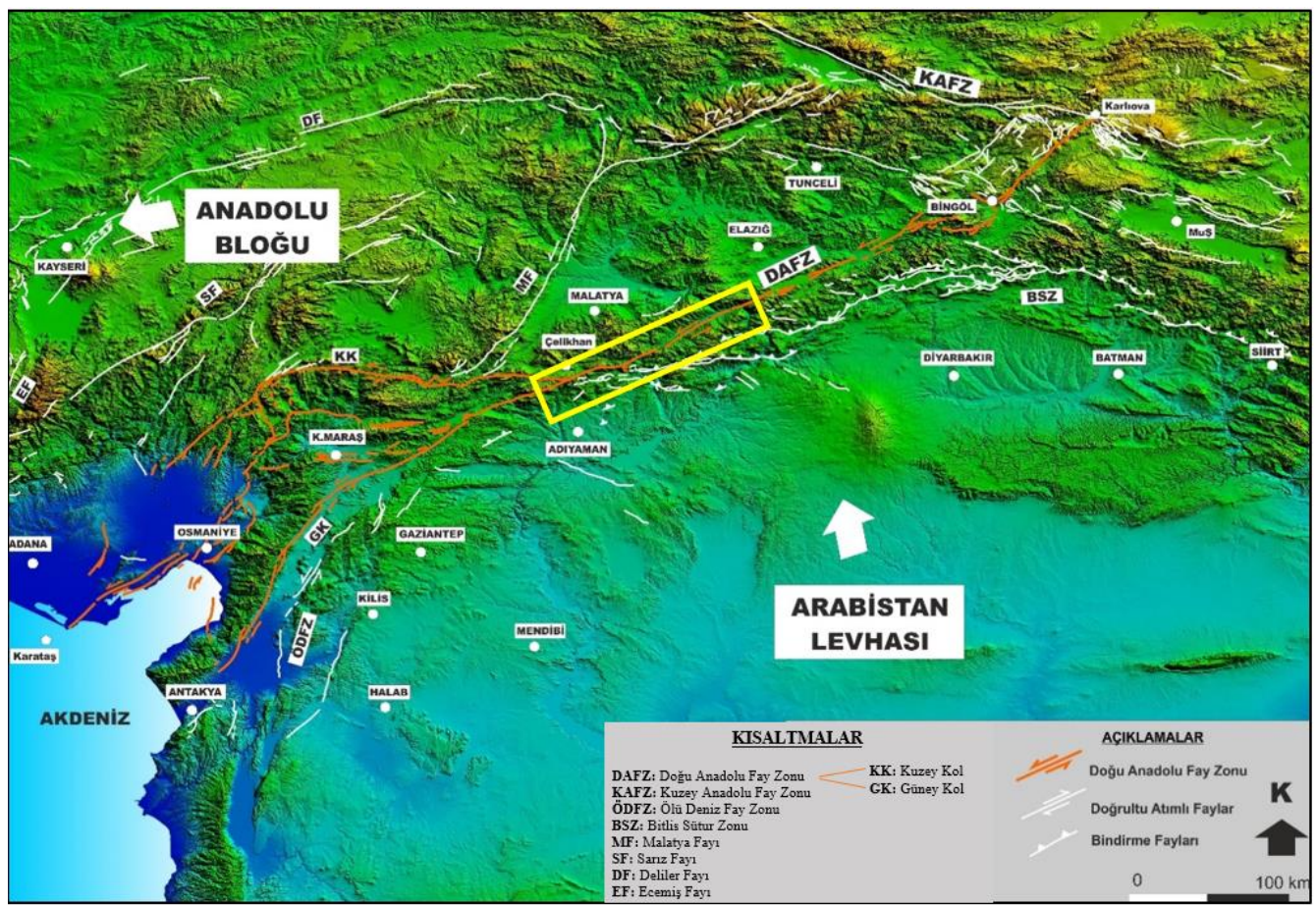

Şekil 1. SRTM görüntüsü üzerinde Doğu Türkiye'deki ana tektonik unsurlar [3] ve çalışma alanının lokasyonu (Büyük beyaz oklar levhaların hareket yönünü göstermektedir) 
24 Ocak 2020 Sivrice (Elazığ)-Doğanyol (Malatya) depreminin (Mw: 6,8, AFAD) de geliştiği inceleme alanındaki aktif tektoniğin birçok disiplinle araştırılması sismik risk analizleri için önem arz etmektedir. Çalışma alanı ve çevresinde uzaktan algılama yöntemleri kullanılarak jeolojik ve tektonik özellikleri belirlemek amacı ile çalışmalar [2,4-7] gerçekleştirilmiştir.

Çizgisellikler jeolojik, morfolojik, ton farklılıkları ve insan yapımı olmak üzere dört grupta toplanabilir. Fay, kırık, eklem setleri ve zayıflık zonlarını kapsayan jeolojik çizgisellikler analiz için en önemli veriyi oluşturmaktadır. Morfolojik çizgisellikleri ise sirtlar, çizgisel vadiler, akarsular ve taraçalar oluşturmaktadır. Jeolojik ve tektonik süreçler sonucu gelişmiş olan bu morfolojik özellikler çizgisellik analizi için bir diğer veri kaynağını oluşturmaktadır. Ton farklılıklarına bağlı oluşan çizgisellikler ise birimlerin litolojik farklılığına, topraktaki nemlilik oranına ve bitki örtüsüne bağlı olarak gelişmektedir. Özellikle doğrultu atımlı fayların farklı birimleri karşı karşıya getirdiği ve birimlerde atıma neden olduğu düşünüldüğünde, uydu görüntülerinde farklı spektral özelliklere sahip litolojik farklılıkların [8] belirlenmesi aktif tektonik çalışmalar için öneme sahiptir. Jeolojik süreçlere bağlı oluşmayan yol, ekili alanlar, binalar, maden ocakları gibi insan yapımı çizgiselliklerin analizlerde değerlendirilmesini engellemek için, bu üç çizgisellik türünün tektonik kökenli olup olmadığı arazi gözlemleri ile kesinlikle denetlenmelidir. $\mathrm{Bu}$ üç çizgisellik türünün tektonik kökenli olup olmadığı arazi gözlemleri ile kesinlikle denetlenmelidir. Bu çalışma için, inceleme alanına ait $30 \mathrm{~m}$ mekânsal çözünürlüğe sahip Landsat 8 OLI (Yörünge 173, Sira 33-34) ile 1 ARC saniye (30x30m) çözünürlüğündeki SRTM (Koordinat: 37N-38E, 37N-39E, 38N-38E, 38N-39E) uydu görüntülerine Amerika Birleşik Devletleri Jeoloji Kurumu (USGS) üzerinden açık erişim ile sağlanmıştır. $15 \mathrm{~m}$ mekânsal çözünürlüğe sahip ASTER uydu görüntüleri de USGS üzerinden ücretsiz olarak elde edilmiştir. Bu çalışmada, mekânsal ve spektral farklılıklara sahip uydu görüntülerinin uzaktan algılama yöntemleri ile iyileştirilerek, aktif tektonik yapıların belirlenmesi amaçlanmıştır.

\section{MATERYAL VE METOT}

Aktif tektoniğin ana araştırma konusu olan faylar ve morfotektonik yapılar arazi çalışmalarına ek olarak uzaktan algılama yöntemleri ile de belirlenebilir. $\mathrm{Bu}$ yöntemler arazi çalışmaları öncesi ve sonrası, alandaki morfotektonik yapıların belirlenmesi ve yorumlanmasında büyük katkı sağlamaktadır. Bu amaçla SRTM (Shuttle Radar Topography Mission) görüntüleri arazinin topoğrafyasını yansıtarak, ana tektonik hatların belirlenmesinde büyük fayda sağlamaktadır. Ayrıca SRTM görüntülerinden sayısal yükseklik modeli (SYM- DEM) elde edilerek drenaj ağları (Şekil 2a) ve istenilen aralıklarda eş yükselti (Şekil 2b) eğrileri üretilebilmektedir. Drenaj ağlarının desenleri ve ötelenmeleri tektonik çalışmalar için anahtar unsurlardır. SYM'den üretilen eş yükselti eğrileri ise morfoloji ve tektonik unsurlar hakkında önemli bilgiler sağlamaktadır.

Landsat 8 uydusu; 30 m mekânsal çözünürlüklü 3 görünür, 1 yakın kızılötesi ve 2 kısa dalga kızılötesi bantları, 100 m mekânsal çözünürlüklü termal bantları, yine $30 \mathrm{~m}$ mekânsal çözünürlüklü olan bulutları (circus) algılayan bandı ve bunlardan ayrı $15 \mathrm{~m}$ mekânsal çözünürlüklü pankromatik bandı olmak üzere 11 banda sahiptir. Landsat 8 görünür, yakın kızılötesi ve k1sa dalga kızılötesi görüntülerinde 8 bit ve termal görüntülerde 12 bit radyometrik çözünürlüğe sahiptir. Zamansal çözünürlüğü 16 gün olan uydu $185 \mathrm{~km}$ tarama genişliği ile geniş bir alanı taramaktadır.

En yüksek mekânsal çözünürlüğe sahip olan 8 . pankromatik bant üzerine uygulanan GramSchmidt (G-S) Pan-sharpening zenginleştirme metodu ile mekânsal ve spektral çözünürlüğü yüksek daha kaliteli bir görüntü elde edilmiştir [9]. Ayrıca doğal arazi görünümü elde etmek için bant kombinasyonu uygulanmıştır. 

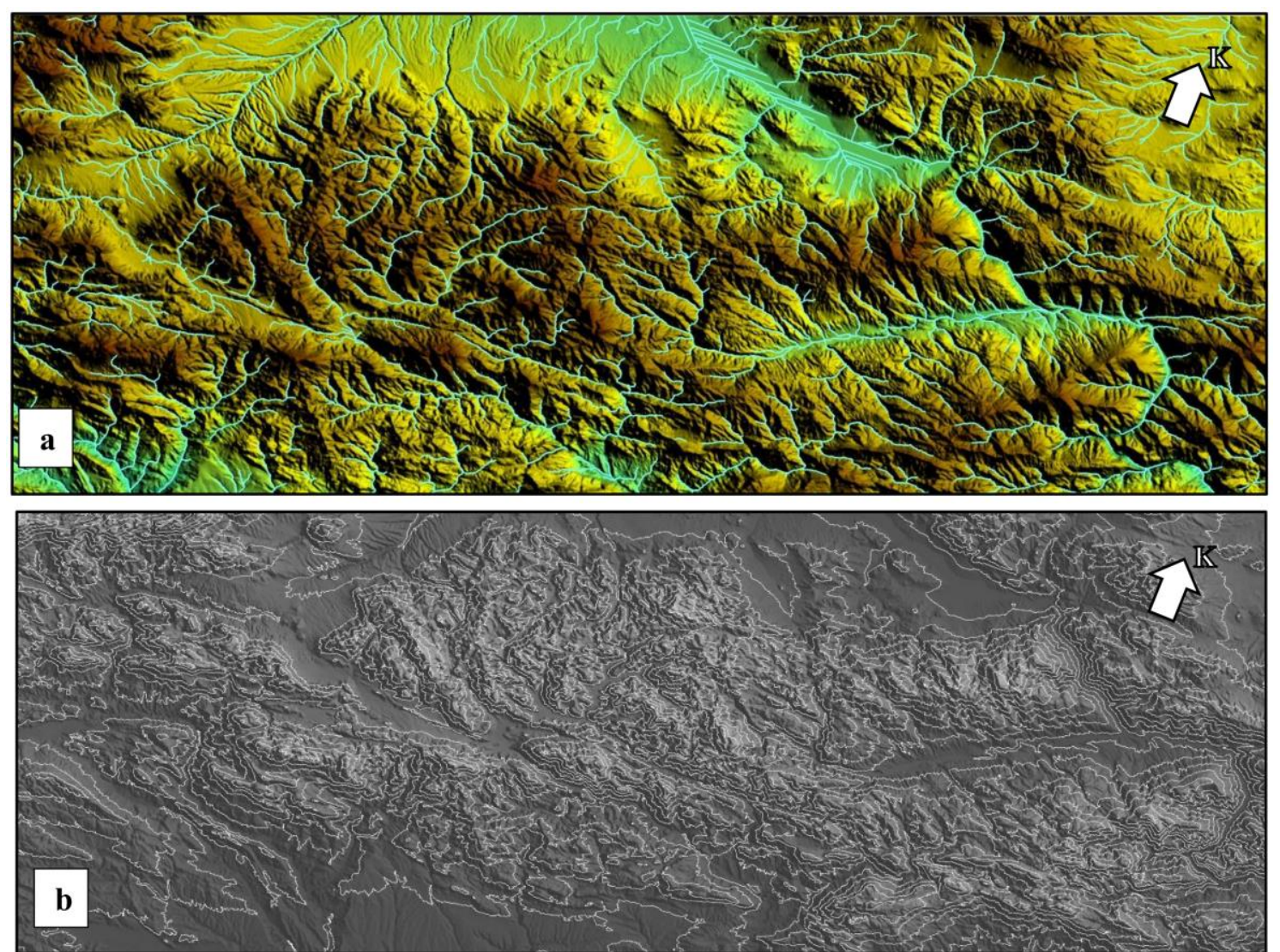

Şekil 2. SRTM görüntülerinden elde edilen Sayısal Yükseklik Modelleri (SYM-DEM), a) SYM'den üretilen drenaj ağı haritası, b) SYM'den üretilen eş yükselti eğrileri

ASTER (The Advanced Spaceborne Thermal Emission and Reflection Radiometer) NASA tarafından TERRA uzay aracı üzerine yerleştirilmiş multispektral görüntüleri kayıt eden gelişmiş bir modüldür. ASTER modülü üç farklı algılayıcıdan oluşmaktadır: Görünür ve YakınK1zılötesi (VNIR) 15 m'lik mekânsal çözünürlüğe sahip 3 bant (Bant 1,2 ve $3 \mathrm{~N}$ ) ve bir bant stereo görüş için geri bakış teleskopu (3B); Kısa Dalga Kızılötesi (SWIR) 30 m'lik mekânsal çözünürlüğe sahip 6 bant ve Termal Kızılötesi (TIR) 90 m'lik mekânsal çözünürlüğe sahip 5 banda sahiptir. VNIR ve SWIR görüntüleri 8 bit, TIR görüntüleri 12 bit radyometrik çözünürlüğe sahiptir. Zamansal çözünürlüğü 16 gün olan uydunun tarama genişliği de 60 km'dir. ASTER uydu görüntüleri, Landsat'a göre yüksek spektral çözünürlüğe sahip olması nedeniyle tektonik ana hatların yanı sıra morfolojik unsurların ve litolojik farklılıkların tespit edilmesini sağlamaktadır. ASTER uydu görüntülerinin yüksek spektral çözünürlügüünden faydalanılarak çok sayıda mineral dağılımına dayalı tematik jeoloji haritaları üretilebilmektedir [10-12].

Uydu görüntüleri indirilirken görüntünün alındığı zamana dikkat edilmiştir. Bunun nedeni uydu görüntülerinde yağışlı aylarda bulut, kış aylarında havanın puslu ve yaz aylarının çok sıcak günlerinde ise buharlaşmanın olmasına bağlı olarak görüntü kalitesinin bozulmasıdır. Görüntüler ön işleme, çeşitli zenginleştirme ve yorumlama teknikleri kullanılarak ENVI 5.1 yazılımı ile işlenmiştir. Düzenli ve düzensiz bilgiler içeren uydu görüntülerinden esas verilerin doğru bir şekilde elde edilebilmesi için 
radyometrik ve geometrik düzeltmeler uygulanarak uydu görüntüleri ön işlemden geçirilir. Görüntüyü yorumlama ve analiz için etkili hale getiren zenginleştirme teknikleri renk ve ton farklılıkları sağlayarak görüntü iyileştirilir. Elde edilmesi planlanan uydu görüntülerini yorumlama tekniklerini bant birleştirme, kontrast zenginleştirmesi (CE), dekorelasyon germesi (DS), kenar germesi (SS) ve temel bileşen analizi (PCA) oluşturmaktadır. $\mathrm{Bu}$ teknik işlemler uydu görüntüsünün yorumlanmasında büyük kolaylıklar sağlamaktadır (Şekil 3). ASTER uydu görüntüleri üzerine uygulanan zenginleştirme ve işleme teknikleri, tektonik hatları daha belirgin hale getirmektedir. Morfolojik çeşitlilik sergileyen doğrultu atımlı faylarda net bir şekilde görülen drenaj ötelenmeleri, aktif tektonik hatların belirlenmesinde kullanılan en güvenilir ölçüttür. [13]. Ayrica fotojeoloji ve uzaktan algılama çalışmalarında drenaj desenlerindeki değişim jeolojik birimlerin sınırlarını [14] dolayısıyla yapısal unsurları da ortaya çıkarabilir.

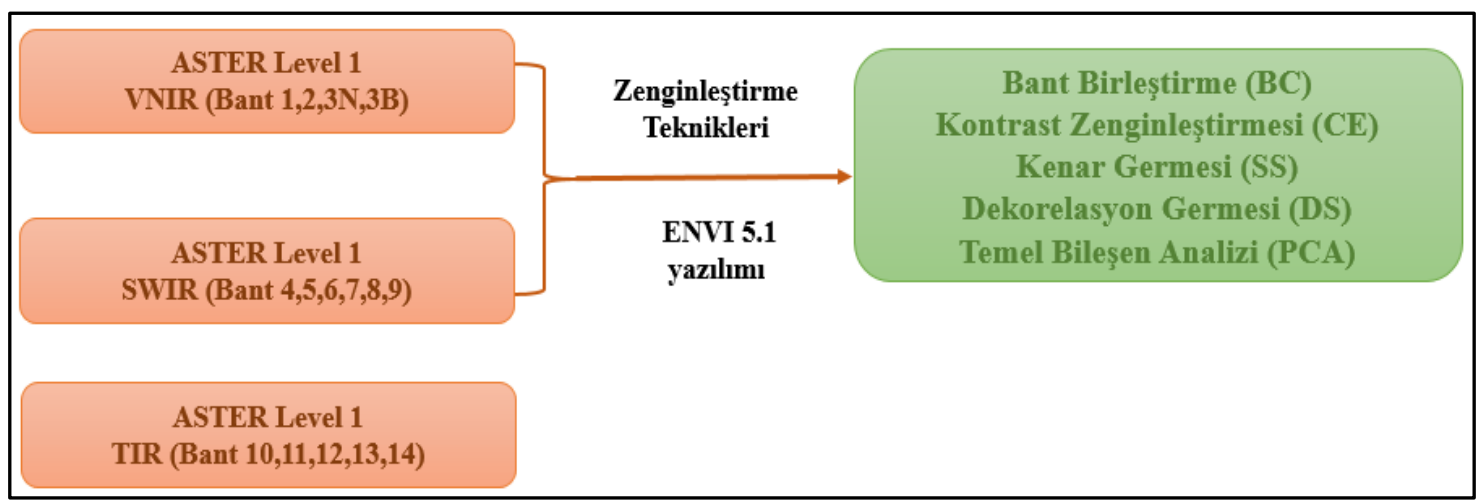

Şekil 3. ASTER uydu görüntülerine uygulanan zenginleştirme yöntemlerinin akış şeması

Bant kombinasyonu uzaktan algilama çalışmalarının en yaygın tekniği olup, görüntüdeki renk kontrastını artırarak uydu görüntüsü üzerindeki verilerin yorumlanmasını sağlamaktadır. Esası temel bileşenler analizi olan dekorelasyon germesi (DS), korelasyonu yüksek olan çok bantlı görüntüler için bir renk zenginleştirme tekniğidir [15]. Dekorelasyon germesinin amacı, bant içerisindeki korelasyonu azaltmak ve gerdirme işlemi ile renk değişimini geliştirmek ve böylelikle görsel yorumlamayı güçlendirmektir. Yeni bir koordinat sistemi hesaplayarak çoklu spektral veri setlerini sıkıştıran bir teknik [16] olan temel bileşen analizi (PCA) gürültüyü filtrelemede ve sistemlerin gruplandırılmasında kullanılan istatistiksel bir yöntemdir. Bu teknik, birden fazla bant üzerine uygulanabilir. Bantlar genellikle birbirleriyle görsel ve sayısal olarak oldukça ilişkilidir. Bu nedenle çok boyutlu veri içerisindeki cisimleri tanımak ve birbirinden ayırmak zorlaşabilir.

\section{BULGULAR}

$\mathrm{Bu}$ çalışmada aktif tektonik hatların belirlenebilmesi için SRTM, Landsat 8 ve ASTER uydu görüntülerine çeşitli görüntü işleme ve zenginleştirme teknikleri uygulanmıştır. Çalışma alanına ait Landsat 8 görüntülerinin $15 \mathrm{~m}$ mekânsal çözünürlüğe ve pankromatik özelliğe sahip 8. bant özelliğinden faydalanarak da uydu görüntüsünden maksimum fayda sağlanmıștır. Arazi görünümü elde edebilmek için uydu görüntüsüne RGB:432 doğal bant kombinasyonu uygulanmıştır. Tektonik yapıları maksimize etmek için SRTM görüntüsü üzerine Landsat 8 OLI doğal renk kombinasyonu eklenerek, yüksek çözünürlüklü 3 boyutlu arazi görünümü elde edilmiştir (Şekil 4). Çalışma alanının Doğanyol (Malatya) kesiminde yaklașı 13 km'lik atıma sahip Firat Nehri boyunca fay zonuna ait segmentler net bir şekilde görülmektedir. Ayrıca fay zonuna paralel gelişmiş uzamış sırtlar ve 
çizgisellikler RGB: 521 renk kombinasyonu ve kenar germesi yöntemleri ile daha belirgin hale getirilirken, Firat Nehri'ni besleyen yan kollardaki ötelenmeler fayın sol yönlü karakterini açıkça göstermektedir (Şekil 5). Segmentin geometrisinin iyi belirlenmesi sismik risk açısından büyük önem taşımaktadır.

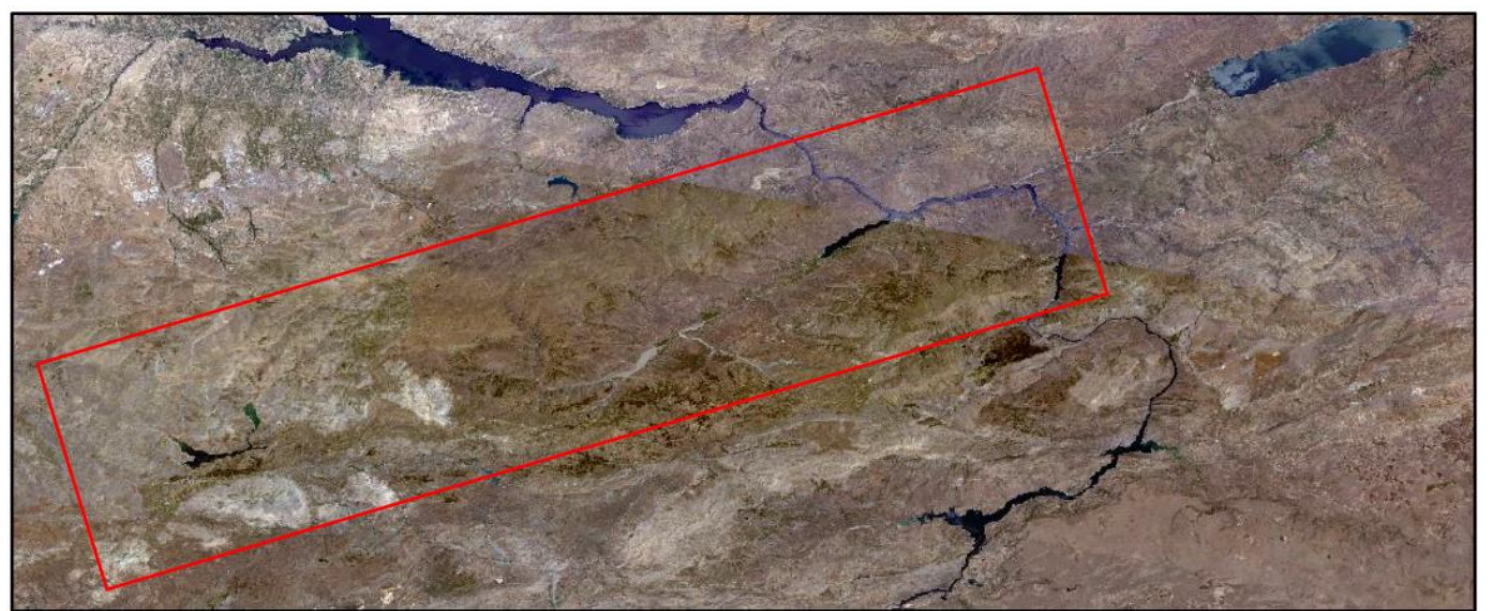

Şekil 4. SRTM görüntüsü ve RGB: 432 doğal bant kombinasyonu uygulanmış Landsat 8 uydu görüntüsünün katmanlı görünümü (kırmızı çerçeve incelenen alanı göstermektedir)

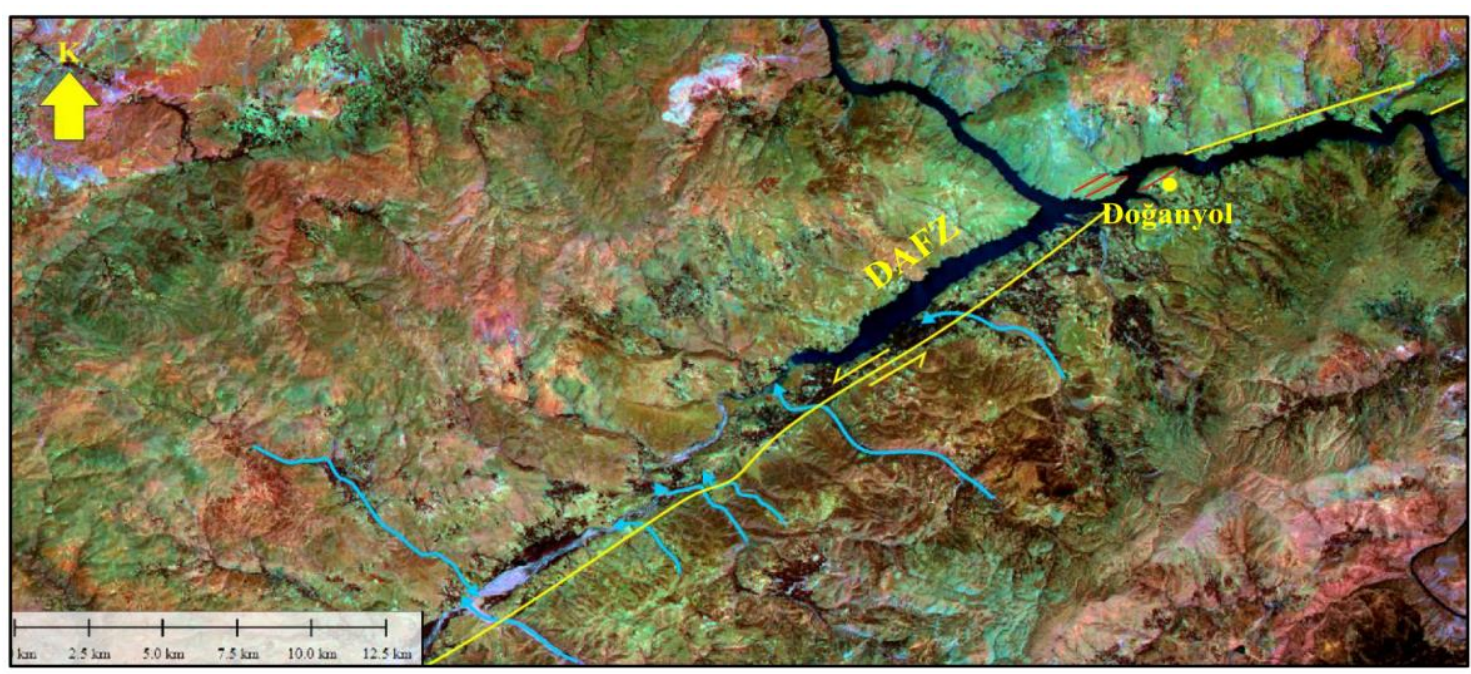

Şekil 5. RGB: 521 bant kombinasyonu ve kenar germesi uygulanmış ASTER uydu görüntüsü, yorumlanmış görünümü (DAFZ: Doğu Anadolu Fay Zonu, sarı çizgiler ana fay zonunu, kırmızı çizgiler faya paralel gelişmiş basınç sırtlarının eksenlerini, mavi çizgiler ise ötelenmiş akarsuları göstermektedir)

Çalışma alanının güneybatı kesimine ait ASTER uydu görüntüsüne uygulanan RGB:321 bant kombinasyonu ile yapay renk bileşimi oluşturulmuştur (Şekil 6a). Ek olarak kenar

germesi uygulanarak, görüntü daha net hale getirilmiştir. Elde edilen görüntüde kırmızı renkli alanlar havzaları ve tarım arazilerini temsil ederken, diğer alanlar ise bölgedeki dayanımlı 
kayaçların oluşturduğu yükseltilerdir. Çelikhan'ın (Adıyaman) hemen doğusunda vadi içerisindeki akarsu ötelenmeleri yaklaşık $100 \mathrm{~m}$ ile $400 \mathrm{~m}$ arasında sol yanal atıma karşılık gelmektedir. DAFZ Çelikhan'ın güneyinde doğrultusunu bir yay gibi değiștirerek Çelikhan havzasının güneydoğusunu sınırlamaktadır. Bu alanda faya paralel gelişmiş basınç sırtları dikkat çekmektedir (Şekil 6b).

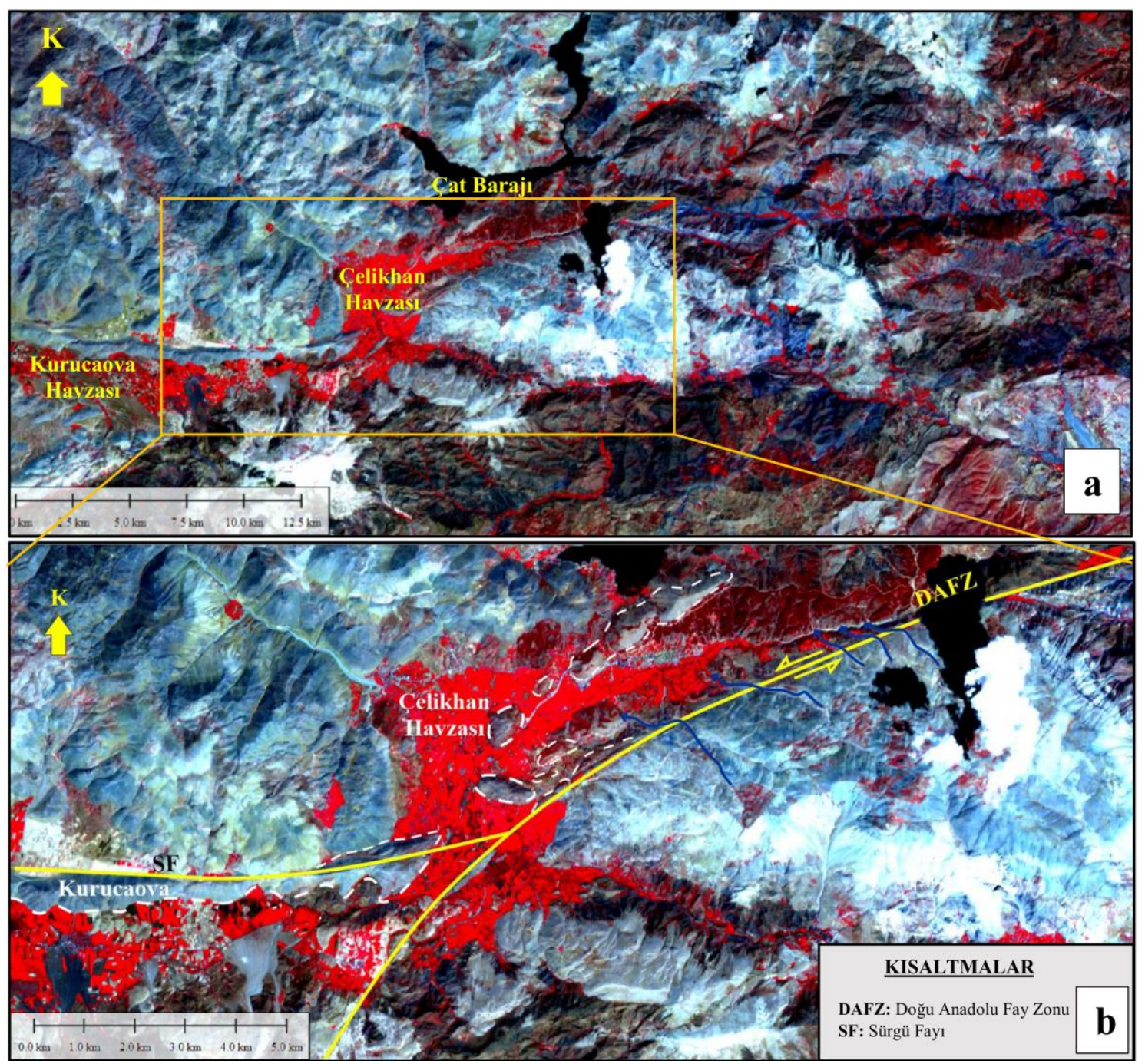

Şekil 6. a) RGB: 321 bant kombinasyonu ve kenar germesi uygulanmış ASTER uydu görüntüsü, b) Çelikhan havzası ve çevresine ait uydu görüntüsünün yorumlanmış hali (sarı çizgiler ana fay zonunu, beyaz kesikli çizgiler faya paralel gelişmiş basınç sırtlarını, mavi çizgiler ise ötelenmiş akarsuları göstermektedir)

Ayrica bu alanda RGB: 421 bant kombinasyonu ile işlenmiş görüntü üzerine dekorelasyon germesi uygulanarak, alandaki litolojik farklılıkları ortaya çıkarılmıştır. Mavi renkli alanlar Malatya Metamorfitleri'ne ait mermerleri, mor alanlar alüvyonları, Turuncu alanlar Maden Karmaşı̆̆ı'na 
ait birimleri, sarı-kahverengi karışımı alacalı alanlar ise Pütürge Metamorfitleri'ne ait kayaçları göstermekte olup, birim sınırları hakkında kabaca da olsa bilgi vermektedir. Birimlerin petrografik, mineralojik ve reolojik farklılıklarından kaynaklı DAFZ ve Sürgü Fayı'nın uzanımı renk kontrastı ile net olarak ayırt edilmektedir (Şekil 7). Ayrıca yaklaşık KD-GB doğrultusundaki baraj gölünün güneyinde mor renkle ayırt edilen Çelikhan Havzası'nda yaklaşık 1 km'lik sol yanal litolojik atım (a-a') söz konusudur. Pliyo-Kuvaterner yaşlı bu havza dolgusunun fay tarafından sol yanal olarak ötelenmesi fayın yaşının oldukça genç olduğunun önemli bir göstergesidir. Bu filtreleme ile litolojik atım net bir şekilde izlenmekte olup, bu alandaki saha çalışmaları sırasında birimin faylı yüzlekleri gözlemlenmiştir. Bir önceki filtrelemede olduğu gibi (Şekil 6), bu filtrelemede de (Şekil 7) dayanımı düşük kayaçlar (alüvyonlar-mor renkli alanlar) ile dayanımı yüksek kayaçlar (Malatya Metamorfitlerine ait mermerler-mavi renkli alanlar) keskin sınırlarla diğer birimlerden ayırt edilmektedir. $\mathrm{Bu}$ anlamda birimin türü ve dayanımı da litolojik ayrımın seçiciliğinde önem taşımaktadır.

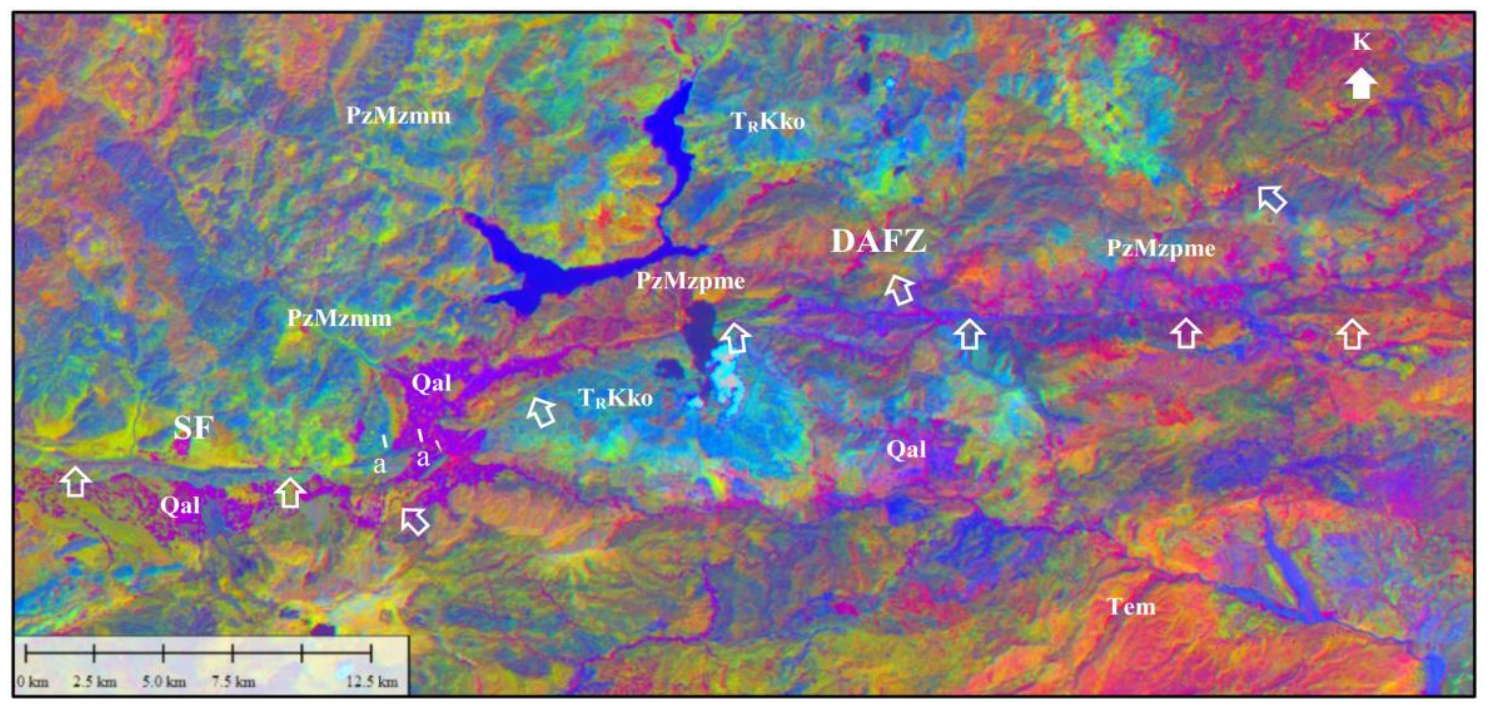

Şekil 7. Çelikhan ve çevresinin RGB: 421 bant kombinasyonu ve dekorelasyon germesi uygulanmış ASTER uydu görüntüsü (PzMzmme: Malatya Metamorfitleri, PzMzpme: Pütürge Metamorfitleri, $\mathrm{T}_{\mathrm{R}}$ Kko: Koçali Ofiyoliti, Tem: Maden Karmaşığı, Qal: Alüvyon, DAFZ: Doğu Anadolu Fay Zonu, SF: Sürgü Fayı, beyaz oklar belirgin fay izini, a-a': 1 km'lik litolojik atımı göstermektedir)

\section{TARTIŞMA VE SONUÇLAR}

Aktif fay zonlarında segmentlerin geometrisi ve faylara bağlı gelişen morfotektonik yapıların iyi belirlenmesi olas1 sismik risk alanlarının belirlenmesi açısından önem taşımaktadır. Uzaktan algılama çalışmaları her ne kadar saha çalışmaları öncesi arazi hakkında önemli veriler elde edilmesini sağlasa da, uydu görüntülerinden elde edilen bulgular saha çalışmaları ile denetlenmeden yorumlanmamalıdir.
$\mathrm{Bu}$ çalışmada tektonik hatların yanı sıra aktif tektonik yorumlama için oldukça önemli olan morfotektonik yapılar da belirlenmiştir. SRTM ve Landsat 8 uydu görüntülerinde tektonik ana hatların ve çizgiselliklerin oldukça belirgin olmasına karşılık; işlenmiş ASTER uydu görüntüleri ise tektonik hatları göstermenin yanı sira, morfotektonik yapıların yorumlanmasında büyük kolaylık sağlamıştır. Ayrıca ASTER uydu görüntülerinin multispektral bant özelliği litolojik birim sınırlarının ayrımında Landsat 8 uydu 
görüntülerine göre daha belirleyici olmuștur. ASTER görüntüsü üzerine uygulanan zenginleştirme teknikleri ile su kütleleri, ekili alanlar kolaylıkla ayırt edilmiştir. Reolojik olarak dayanımlı litolojik birimlerin rölyefi ve tonu diğer birimlerden farklılık göstermektedir. Özellikle Çelikhan Havza'sını dolduran çökelleri oluşturan genç birimlerin fay tarafından sol yanal ötelenmesinin açıkça görülmesi, fayın yaşının yorumlanmasına imkân vermiştir. Bu alandaki litolojik birimlerin sınırları Doğu Anadolu Fay Zonu boyunca gerçekleştirilen jeolojik harita çalışmalarındaki [17] birim sınırları ile uyumludur (Şekil 8).

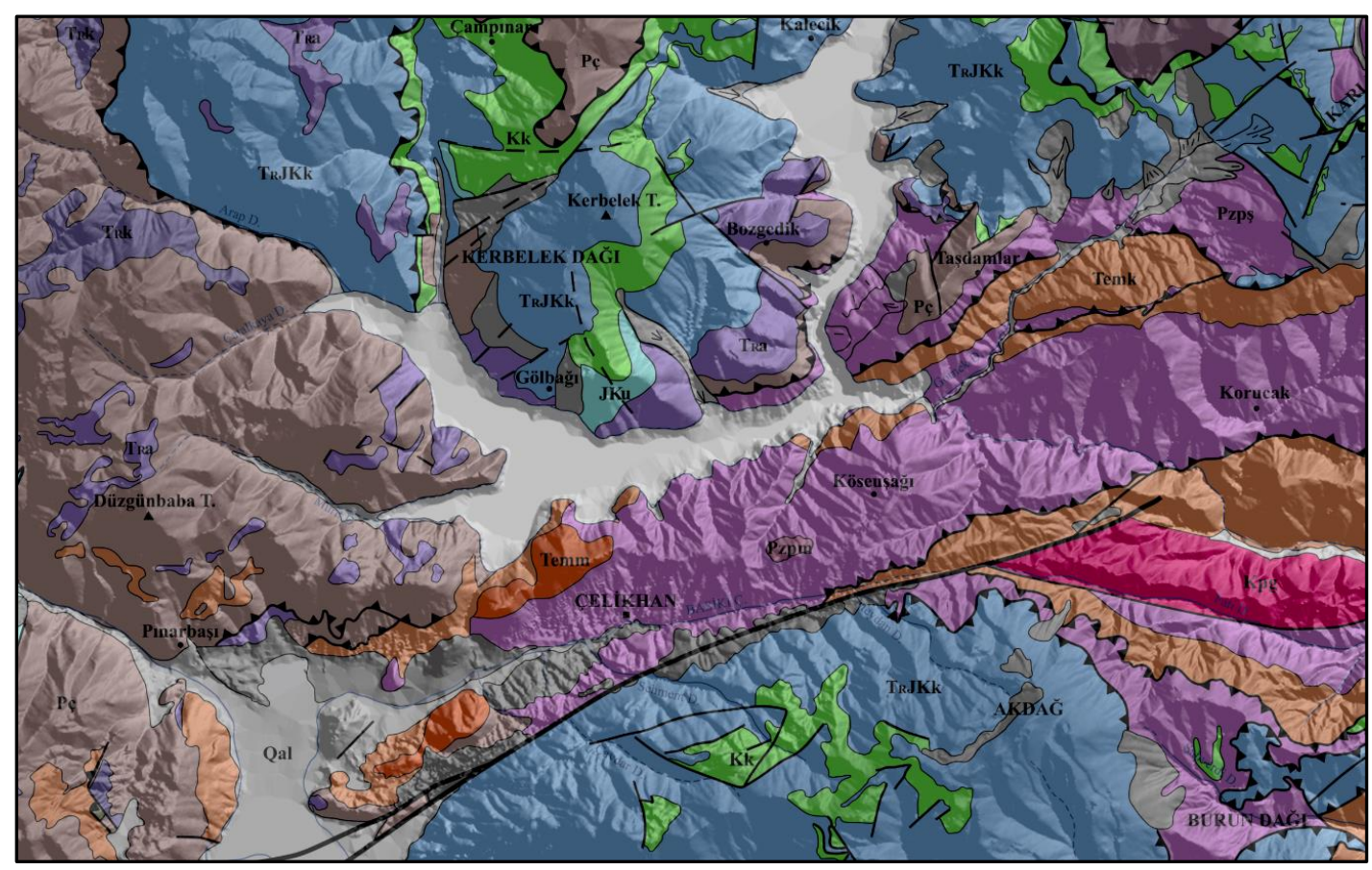

Şekil 8. Çelikhan ve çevresinin jeoloji haritası [17]

Özellikle su kütlesi ve Çelikhan havzası içerisindeki genç dolgunun sınırları her iki uydu görüntüsünde de keskin hatlarla belirgindir. Ancak ASTER görüntülerine uygulanan zenginleştirme teknikleri (Şekil 7) saha çalışmalarına dayalı jeolojik harita (Şekil 8) ile karşılaştırıldığında, litolojik sınırların ayırt edilmesinde, multispektral özelliğin litolojik sınırlardaki belirleyici özelliği açıkça görülmüştür.

Çeşitli uydu görüntülerinin (ASTER, Landsat 8 OLI, Sentinel-2A MSI) işlenmesine dayalı gerçekleştirilen bant kombinasyonu ve bant oranlama teknikleri [6,7] litolojik birimleri etkileyen faylı bölgelerde litolojik birimlerin yanı sıra bu birimlerin sınırlarındaki ötelenmelerin belirlenmesinde de önemli rol oynamıştır.
Çalışmadaki en fazla veri ASTER uydu görüntüleri üzerine uygulanan zenginleştirme teknikleri ile elde edilmiştir. Landsat 8 OLI uydu görüntüleri işlenerek çalışma alanında daha önce çizgisellik analizi gerçekleştirilmiştir [4]. Özel ve yönlü filtreleme teknikleri uygulanarak manuel olarak çıkarılan çizgisellikler, DAFZ' nin KD-GB doğrultusunu ve yaklaşık D-B doğrultulu bindirme kuşağını açıkça yansıtmıştır. Landsat 8 uydu görüntüsündeki $15 \mathrm{~m}$ mekânsal çözünürlüğe ve pankromatik özelliğe sahip 8. bant, çizgiselliklerin belirginleşmesini ve görsel yorumlamayı kolaylaştırmıştır. $\mathrm{Bu}$ çalışmada belirlenen morfotektonik özellikler, [4] tarafından gerçekleştirilmiş çizgisellik analizinin sonucu ile uyumlu olup, DAFZ'nin KD-GB uzanımını ve sol yanal karakterini açıkça yansıtmaktadır. 


\section{KAYNAKLAR}

1. Kaymakçı, N., İnceöz, M., Ertepinar, P., 2006. 3D Architecture and Neogene Evolution of the Malatya Basin: Inferences for the Kinematics of the Malatya and Ovacik Fault Zones, Turkish Journal of Earth Sciences, 15, 123-154.

2. Koç, A., Kaymakç1, N., 2013. Kinematics of Sürgü Fault Zone (Malatya, Turkey): A Remote Sensing Study, Journal of Geodynamics, 65, 292-307.

3. Duman, T.Y., Emre, Ö., 2013. The East Anatolian Fault: Geometry, Segmentation and Jog Characteristics, Geological Society London, Special Publications, 19.

4. Akgün, E., İnceöz, M., Manap, H.S., 2019. Geological Lineament Analyses Application to a Fault Segment on the East Anatolian Fault Zone, $18^{\text {th }}$ International Multidisciplinary Scientific GeoConference SGEM 2018, Albena, Bulgaria.

5. Köküm, M., 2019. Landsat TM görüntüleri Üzerinden Doğu Anadolu Fay Sistemi'nin Palu (Elazığ)-Pütürge (Malatya) Arasındaki Bölümünün Çizgisellik Analizi, Gümüşhane Üniversitesi Fen Bilimleri Enstitüsü Dergisi, 9(1), 119-127.

6. Khalifa, A., Çakır, Z., Kaya, Ş., Gabr, S., 2020. ASTER Spectral Band Ratios for Lithological Mapping: a Case Study for Measuring Geological Offset Along the Erkenek Segment of the East Anatolian Fault Zone, Turkey, Arabian Journal of Geosciences, 13, 832.

7. Zabc1, C., 2021. Çok bantlı Landsat 8-OLI ve Sentinel-2A MSI Uydu Görüntülerinin Karşılaştırmalı Jeoloji Uygulaması: Örnek Çalışma Alanı Olarak Doğu Anadolu Fayı Boyunca Palu-Hazar Gölü Bölgesi (Elazığ, Türkiye), Geomatik, 6(3), 238-246.

8. Nguyen, P.T., Ho, D., 1988. Multiple Source Data Processing in Remote Sensing, Digital Image Processing in Remote Sensing, 153-176.

9. Doski, J.A.H., 2019. Tectonic Analaysis of Lineaments in the Gara Anticline, Northern Iraq, Journal of Indian Society of Remote Sensing.
10. Vander Meer, F., 1997. What Does Multisensor Image Fusion add in Terms of Information Content for Visual İnterpretation?, International Journal of Remote Sensing, 18, 445- 452.

11. Rowan, L.C., Mars, J.C., 2003. Lithologic Mapping in the Mountain Pass, California Area Using Advanced Spaceborne Thermal Emission and Reflection Radiometer (ASTER) Data, Remote Sensing of Enviroment, 84, 350-366.

12. Manap, H.S., San, B.T., 2018. Lithological Mapping Using Different Classification Algorithms in Western Antalya, Turkey, $18^{\text {th }}$ International Multidisciplinary Scientific GeoConference SGEM 2018, Albena, Bulgaria.

13. Akgün, E., 2020. Doğu Anadolu Fay Zonu'nun Doğanyol (Malatya) ile Çelikhan (Adıyaman) Arasindaki Gerilme Durumunun İncelenmesi, Doktora Tezi, Fen Bilimleri Enstitüsü, Frrat Üniversitesi, Elazı̆̆ 116.

14. Brockmann, C.E., Fernandez, A., Ballon, R., Claure, I.I., 1977. Analysis of Geological Structures Based on Landsat-1 Images, Remote Sensing Applications for Mineral Exploration, 292-317.

15. Sümer, E.Ö., San, B.T., Gürçay, B., Pekesin, B.F., Avc1, M.K., Koruyucu, M., Dağlıyar, A., Teoman, Ş., Topçu, T., Özgüner, C., 2006. ASTER Uydu Verisi Uygulamalar1; Türkiye'den Örnekler, MTA Özel Yayın Serisi, 5,71 .

16. Sabins, F.F., 1987. Remote Sensing Principles and Interpretation, $2^{\text {nd }}$ ed., W.H. Freeman and Company, NewYork, 481.

17. Herece, E., 2008. Atlas of East Anatolian Fault. General Directorate of Mineral Research and Exploration, Special Publication Series 13, 359. 